\title{
Meneropong Teks dalam Konteks: Katekismus Heidelberg P/J 53'
}

\author{
Freddy Gunawan* \\ *Penulis adalah lulusan program M.Th. Teologi di Sekolah Tinggi Teologi Reformed Indonesia, dosen Teologi \\ Sistematika dan Perjanjian Baru di Sekolah Tinggi Teologi IMAN Jakarta, dan rohaniwan di Gereja Santapan \\ Rohani Indonesia Taman Sari Jakarta. \\ Email: freddyg07@gmail.com
}

\begin{abstract}
Abstrak: Katekismus Heidelberg merupakan salah satu warisan tradisi iman Reformed yang memuat pengajaran yang begitu kaya dan limpah mengenai doktrin Allah Roh Kudus. Secara eksplisit, pengajaran tentang doktrin Allah Roh Kudus dalam Katekismus Heidelberg memang hanya terdapat dalam P/J 53. Namun, hal ini tidak berarti bahwa pengajaran doktrin Allah Roh Kudus dalam Katekismus Heidelberg hanya termaktub di dalam bagian ini saja. Tulisan ini mencoba menganalisis kekayaan doktrin Allah Roh Kudus, secara khusus P/J 53, dalam tiga konteks: konteks masa lalu yang menjadi latar belakang terbentuknya Katekismus Heidelberg, konteks makro dan mikro P/J 53 secara tekstual, dan relevansinya bagi konteks masa kini, khususnya Indonesia.
\end{abstract}

Kata-kata kunci: Katekismus Heidelberg, P/J 53, Roh Kudus, penghiburan, penyertaan, konteks masa lalu, konteks tekstual, konteks masa kini

\begin{abstract}
The Heidelberg Catechism reflects a rich heritage within the Church that adheres to the Reformed tradition. It contains a rich strain of doctrine pertaining to the doctrine of the Holy Spirit. Explicitly, within the Heidelberg Catechism, the teaching regarding the doctrine of the Holy Spirit as a Member of the Godhead is found only in Question/Answer 53. Of course, this does not mean that the only teaching on the subject of the doctrine of the Holy Spirit within the Heidelberg Catechism is recorded in this section alone. The purpose of this essay is an attempt to conduct an analysis of the doctrine of the Holy Spirit, specifically Q/A 53, from three different contexts: the historical setting which reflects the historical context in which the Heidelberg Catechism was formulated, a macro and micro textual analysis of Q/A 53 within the context of the Heidelberg Catechism, and finally, the relevancy of the document for the contemporary context, especially focusing upon the Indonesian context.
\end{abstract}

Keywords: Heidelberg Catechism, Question/Answer 53, The Holy Spirit, Consolation, Abiding, Historical Context, Textual Context, Contemporary Context

\footnotetext{
${ }^{1}$ Semua teks $\mathrm{P} / \mathrm{J}$ dalam makalah ini diambil dari Zakharias Ursinus dan Caspar Olevianus, Katekismus Heidelberg: Pengajaran Agama Kristen, ed. rev., terj. Tim BPK Gunung Mulia (Jakarta: BPK Gunung Mulia, 2013). 


\section{Pendahuluan}

Dalam Katekismus Heidelberg (selanjutnya disingkat $\mathrm{KH}$ ), satu-satunya teks yang menjelaskan secara eksplisit pribadi Roh Kudus dalam $\mathrm{KH}$ hanyalah $\mathrm{P} / \mathrm{J}$ 53. Hal ini memunculkan tuduhan bahwa KH sesungguhnya sangat miskin dan minim dalam pengajaran akan Roh Kudus sehingga tidak memberikan signifikansi yang berarti bagi kehidupan gereja. ${ }^{2}$ Tulisan ini digagas sebagai sanggahan terhadap tuduhan tersebut. Analisis terhadap $\mathrm{P} / \mathrm{J} 53$ akan dilakukan dalam tiga konteks. Konteks pertama, penulis akan mengulas kebermaknaan $\mathrm{P} / \mathrm{J} 53$ dalam konteks yang melatarbelakangi terbentuknya $\mathrm{KH}$ (past context). Konteks kedua, penulis akan menelusur konteks tekstual P/J 53 dalam desain keseluruhan $\mathrm{KH}$ sendiri, baik secara makro maupun mikro (textual context). Terakhir, konteks ketiga, penulis akan menjelaskan relevansi $\mathrm{P} / \mathrm{J} 53$ ke dalam konteks kekristenan dan Indonesia masa kini (present context).

\section{Konteks Pertama (Past Context)}

KH merupakan karya monumental yang lahir dari kegelisahan seorang gubernur (elector) wilayah Palatina, wilayah otonomi bagian Kekaisaran Jerman, Frederick III (15151576), atas perpecahan dan permusuhan yang terjadi di antara gereja-gereja di wilayah yang beribukotakan Heidelberg pada waktu itu. Masing-masing kelompok saling berseteru sambil mengangkat tinggi panji-panji teologinya sendiri, baik dari kalangan Kristen Protestan Lutheran garis keras dan moderat, Reformed, Zwinglian maupun dari kalangan Katolik Roma. ${ }^{3}$

Gonjang-ganjing ini sangat meresahkan dan mengancam kehidupan masyarakat dalam bergereja dan bernegara. Eskalasi konflik yang terjadi semakin meningkat dan menjurus kepada kekerasan. Jemaat pun merasa

${ }^{2}$ Eugene P. Heideman, "God the Holy Spirit," dalam Guilt, Grace, and Gratitude: A Commentary on the Heidelberg Catechism, ed. Donald J. Bruggink (New York: The Half Moon, 1963), 112.

${ }^{3}$ Lyle D. Bierma, An Introduction to Heidelberg Catechism: Sources, History, and Theology (Grand Rapids, Michigan: Baker, 2005), 49-50. terancam, mereka tidak dapat beribadah dan menghidupi iman mereka dengan hati yang damai dan penuh pengharapan. Oleh karena itu, Frederick III berusaha agar Palatina kembali lagi dituntun dalam kehidupan saleh yang benar serta damai. ${ }^{4}$

Atas rekomendasi dari Petrus Martyr Vermigli (1449-1562), seorang teolog Italia yang menganut paham Reformasi, maka Frederick III meminta Caspar Olevianus, seorang teolog muda murid Philip Melanchton dan Petrus Martyr Vermigli, dan Zakharias Ursinus, seorang pemuda dengan semangat Reformasi yang fasih dalam berkhotbah menurut rekomendasi Wenceslaus Zuleger (1530-1596), ketua Dewan Gereja waktu itu, untuk menyusun satu katekismus yang bertujuan untuk mempromosikan terciptanya persatuan serta kehidupan yang aman dan damai di antara gereja-gereja. ${ }^{5}$ Oleh karena itu, tidak heran kalau $\mathrm{KH}$, memiliki karakteristik yang unik dan tidak seperti kebanyakan katekismus lain. Gaya penulisannya sangat hangat dan personal, aplikatif dan relevan bagi kehidupan jemaat pada waktu itu. ${ }^{6}$ Selain itu, untuk setiap kata yang dipilih, Frederick bahkan menolak apabila katekismus ini berasal dari kata-kata Calvin atau Luther, melainkan katakata yang dipilih benar-benar bersumber dari firman Allah supaya tidak menimbulkan per-

\footnotetext{
${ }^{4}$ Mariani Febriana Lere Dawa, Penghiburan dan Sukacitaku Selamanya: Suatu Uraian Katekismus Heidelberg (Malang: Bayumedia, 2014), 5.

${ }^{5}$ Thea B. Van Halsema, Three Men Came to Heidelberg and Glorious Heretic: The Story of Guido de Brès (Grand Rapids: Baker, 1991), 31, 38, dikutip dalam Dawa, Penghiburan dan Sukacitaku Selamanya, 6 n. 8, 7 n. 9.

${ }^{6}$ Dawa, Penghiburan dan Sukacitaku Selamanya, 5. Sebelum KH terbentuk secara utuh dan sempurna (1563), beberapa pedoman pengajaran iman Kristen yang dipakai sebelumnya adalah: Katekismus Kecil Luther (1529), Katekismus Besar Luther (1529), Katekismus Brenz (1535), Eine Kurze Ordenlince Summa (A Brief Orderly Summary, 1558), Katekismus Kecil Ursinus (1562), Katekismus Besar Ursinus (1562) (lihat lebih detail, Wim Verboom, "The Completion of the Heidelberg Catechism," dalam The Church's Book of Comfort, ed. Willem Van 'T Spijker, terj. Gerrit Bilkes (Grand Rapids: Reformed Heritage Books, 2009), 28-61.
} 
tentangan dan percecokan yang lebih parah lagi bagi kondisi keagamaan pada waktu itu. ${ }^{7}$

$\mathrm{KH}$ dibingkai oleh satu tema utama, yaitu penghiburan. Tujuannya adalah agar jemaat dapat melihat seluruh penghayatan atas kebenaran Alkitab yang terkandung dalam $\mathrm{KH}$ sebagai sumber penghiburan yang dapat memberikan kekuatan dan pengharapan bagi mereka di tengah karut-marut agama yang sedang terjadi pada waktu itu. ${ }^{8}$ Allah Roh Kudus adalah sumber penghiburan sejati yang selalu menyertai mereka apa pun keadaan yang mereka alami. Pokok ini jugalah tersirat dan termaktub dalam KH P/J 53 sebagaimana yang dianalisis di bawah ini.

\section{Konteks Kedua (Past Context)}

\section{Analisis Struktur Teks ${ }^{9}$}

Apakah yang Saudara percayai tentang Roh Kudus?

Pertama, bahwa Dia bersama dengan Bapa dan Anak

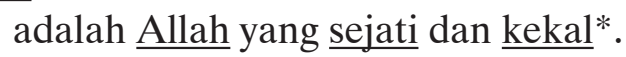

Kedua, bahwa Dia dikaruniakan juga kepadaku$^{* *}$,

supaya Dia membuat aku, oleh iman yang sejati,

beroleh bagian dalam Kristus dan segala anugerah-Nya ${ }^{* * *}$, menghibur aku****,

dan menyertai aku untuk selama-lamanya $* * * *$.

*1 Yohanes 5:7: "Sebab ada tiga yang memberi kesaksian di dalam sorga: Bapa, Firman dan Roh Kudus; dan ketiganya adalah satu."

**Galatia 4:6: "Dan karena kamu adalah anak, maka Allah telah menyuruh Roh AnakNya ke dalam hati kita, yang berseru: "ya Abba, ya Bapa!"

***Galatia 3:14: "Yesus Kristus telah membuat ini, supaya di dalam Dia berkat Abraham sampai kepada bangsa-bangsa lain, sehingga oleh iman kita menerima Roh yang telah dijanjikan itu."

****Yohanes 15:26: "Jikalau Penghibur yang akan Kuutus dari Bapa datang, yaitu Roh Kebenaran yang keluar dari Bapa, Ia akan bersaksi tentang Aku."

*****\%ohanes 14:16: "Aku akan minta kepada Bapa, dan Ia akan memberikan kepadamu seorang Penolong yang lain, supaya Ia menyertai kamu selama-lamanya."

Bila digambarkan dalam bentuk bagan, maka sesungguhnya terdapat beberapa uraian teologis yang berusaha menjelaskan mengenai siapakah pribadi Roh Kudus beserta karyakarya-Nya sebagaimana yang termuat di dalam struktur teks KH P/J 53 di atas.

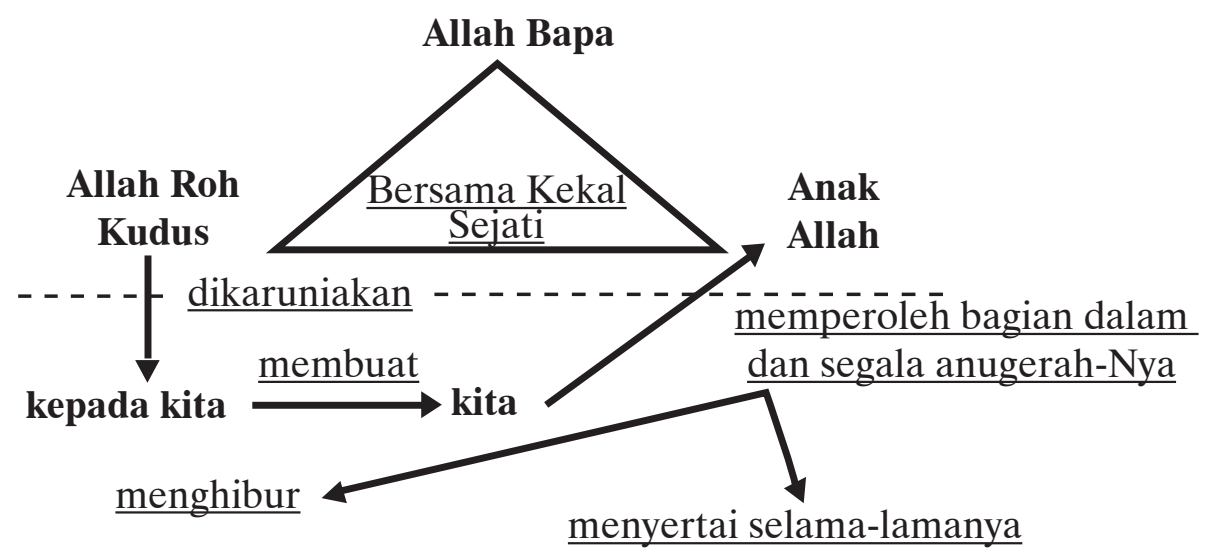

${ }^{7}$ Tim Departemen Dogma dan Penelitian Sinode Gereja Kristus Tuhan dan Staf Pengajar STT Aletheia, Renungan Harian menurut Katekismus Heidelberg I (Surabaya: Rachmat Printing, 2011), 4.

${ }^{8}$ Bierma, An Introduction to Heidelberg Catechism, 52.

${ }^{9}$ Fred H. Klooster, A Mighty Comfort (Grand Rapids: CRC, 1990), 60. 
Dari ilustrasi di atas, dapat dikatakan bahwa Roh Kudus bersama Anak dengan Bapa adalah Allah Tritunggal sejak dari kekal. Roh Kudus tidak hanya ada di atas sana, tetapi juga dikaruniakan secara personal kepada kita, orang percaya, sehingga kita dapat menikmati keseluruhan anugerah dan mengambil bagian dalam Kristus. Setelah itu, barulah Roh Kudus menyatakan penghiburan dan penyertaan-Nya dalam hidup kita.

\section{Analisis Konteks Makro}

Memang apabila dilihat dari makrostruktur $\mathrm{KH}$ secara keseluruhan, secara tersirat hanya $\mathrm{KH} \mathrm{P/J} 53$ yang secara eksplisit menjadi teks yang menjelaskan tentang Roh Kudus dan pengudusan kita: ${ }^{10}$

\begin{tabular}{|l|l|l|}
\hline$H C Q / A$ & Part & Content \\
\hline 1 & & Our only comfort \\
\hline 2 & & Introduction of three parts \\
\hline $3-11$ & I - Misery & \\
\hline $3-11$ & & Law, sin, punishment \\
\hline $12-85$ & II - Deliverance & \\
\hline $12-22$ & & Satisfaction, mediator, faith \\
\hline $23-25$ & Apostolic Creed & Creed, Trinity \\
\hline $26-28$ & God the Father and our creation & Creation, providence \\
\hline $29-52$ & God the Son and our redemption & Name and history of Jesus Christ \\
\hline $53-58$ & God the Spirit and our sanctification & Spirit, church, forgiveness, resurrection \\
\hline $59-64$ & & Justification, good works \\
\hline $65-68$ & Sacraments & General introduction \\
\hline $69-74$ & Holy Baptism & \\
\hline $75-82$ & Lord's Supper & \\
\hline $83-85$ & & Keys of God's kingdom \\
\hline $86-91$ & III - Thankfulness & \\
\hline $86-91$ & & Good works, conversion \\
\hline $92-113$ & Ten Commandments & \\
\hline $114-115$ & & Use of the law \\
\hline $116-129$ & The Lord's Prayer & \\
\hline
\end{tabular}

\footnotetext{
${ }^{10}$ Thorsten Latzel, Theologische Grundzüge des Heidelberger Katechismus: eine fundamentaltheologische Untersuchung seines Ansatzes zur Glaubenskommunikation, volume 83 dari Marburger theologische Studien (Marburg: N. G. Elwert, 2004) 94-97, 101, seperti dicuplik dalam Hans Burger, "Gospel Presentation and the Structure of the Heidelberg Catechism," diakses pada 11 Desember 2014, https:// www.academia.edu/3772581/Gospel_Presentation_and_the Structure_of_the_Heidelberg_Catechism.
} 
Namun perlu diperhatikan secara lebih saksama bahwa jawaban pertama $\mathrm{P} / \mathrm{J} 53$ sesungguhnya merupakan penegasan ulang dari jawaban pertanyaan 24 dan pertanyaan jawaban 25 yang adalah berikut: ${ }^{11}$

Pertanyaan 24: Pengakuan Iman itu dibagi atas berapa bagian? Jawaban: Tiga bagian. Yang pertama mengenai Allah Bapa dan penciptaan kita. Yang kedua mengenai Allah Anak dan penebusan kita. Yang ketiga mengenai Allah Roh Kudus dan pengudusan kita.

Pertanyaan 25: Mengingat bahwa hanya ada satu Zat ilahi saja (Ul. 6:4), apa sebabnya Saudara menyebut Bapa, Anak, dan Roh Kudus? Jawaban: Karena demikianlah Allah menyatakan diri-Nya di dalam Firman-Nya (1Yoh. 5:7). Ketiga Pribadi yang berbeda-beda itu merupakan Allah yang esa, yang sejati dan kekal (2Kor. 13:13).

Masing-masing teks ini saling melengkapi dan menegaskan bahwa Roh Kudus adalah salah satu Pribadi Allah yang kekal, berbeda dengan Allah Bapa dan Anak, dan karya-Nya adalah menguduskan kita, orang percaya yang sudah dilahirbarukan.

Kemudian, bagian kedua dari jawaban pertanyaan 53 berkaitan erat dengan $\mathrm{P} / \mathrm{J} 20$ di mana Roh Kudus yang dikaruniakan secara pribadi kepada kita, mengerjakan iman yang sejati dalam kita sehingga kita mendapat bagian dalam Kristus dan menerima segala aplikasi karya penebusan-Nya (P/J 65) dalam penghiburan dan penyertaan persekutuan dengan Roh-Nya selama-selamanya (P/J 1). ${ }^{12}$

Pertanyaan 1: Apakah satu-satunya penghiburan Saudara, baik pada masa hidup maupun pada waktu mati? Jawaban: Bahwa aku, dengan tubuh dan jiwaku, baik pada masa hidup maupun pada waktu mati (Rm. 14:7, 8) ... milik Yesus Kristus, Juruselamatku yang setia (1Kor. 3:23), dengan darah-Nya yang tak ternilai harganya Dia telah melunasi seluruh hutang dosaku (1Ptr. 1:18, 19) . . k karena itu juga, oleh Roh-Nya yang kudus, Dia memberiku kepastian mengenai hidup yang kekal (2Kor. 1:22).

Pertanyaan 20: Apakah semua orang diselamatkan oleh Kristus, sama seperti mereka telah terkutuk oleh karena Adam? Jawaban: Tidak semua orang (Mat. 7:14), tetapi hanya mereka yang oleh iman yang sejati dijadikan anggota tubuh-Nya dan menerima segala karunia-Nya (Yoh. 1:12).

Pertanyaan 21: Apakah iman yang sejati itu? Jawaban: Iman yang sejati ... dikerjakan dalam hatiku oleh Roh Kudus (Ef. 2:8), melalui Injil (Rm. 10:17).

Pertanyaan 65: Mengingat bahwa hanya iman yang membuat kita mendapat bagian dalam Kristus dan segala anugerah-Nya, dari manakah datangnya iman yang demikian? Jawaban: Dari Roh Kudus (Ef. 2:8).

Jadi, kekayaan pembahasan dan pengajaran tentang pribadi Roh Kudus beserta karya-Nya dalam hidup orang percaya di $\mathrm{P} / \mathrm{J} 53$ sesungguhnya sangatlah limpah dan tidak berdiri sendiri, tetapi terhubung erat dengan $\mathrm{P} / \mathrm{J}$ lainnya dalam makrostruktur $\mathrm{KH}$ secara keseluruhan.

\section{Konteks Mikro KH P/J 53}

Bagian ini secara lebih spesifik akan menguraikan dan juga sekaligus menjelaskan kekayaan dan kedalaman makna teologis yang terkandung dalam KH P/3 53.

\footnotetext{
${ }^{11}$ Dawa, Penghiburan dan Sukacitaku Selamanya, 186.

${ }^{12}$ Ibid., 187-188.
} 
"Dia Bersama dengan Bapa dan Anak"

Roh Kudus "bersama" dengan Bapa dan Anak. Kata yang dipakai di sini "bersama" dan bukan "seperti." Hal ini ingin menyatakan bahwa yang menjadi poin penekanan di sini adalah pribadi Roh Kudus berbeda dengan pribadi Bapa dan Anak. Selain itu, dalam bahasa Inggris kata yang dipakai adalah "together with." Kata ini menunjuk kepada adanya suatu "togetherness" di antara pribadi Bapa, Anak, dan Roh Kudus, di mana terdapat suatu keselarasan yang total dan sempurna di dalam keseluruhan gerak dan langkah dari ketiga pribadi ilahi tersebut. ${ }^{13}$

Ia disebut "Roh" secara khusus bukan karena Ia memiliki natur yang lebih rohani atau spiritual daripada Bapa dan Anak. ${ }^{14}$ Begitu pula, Ia disebut "Kudus" bukan karena Ia lebih kudus dari Bapa dan Anak. Penyebutan ini adalah untuk menekankan bahwa Ia berbeda dengan roh yang najis. ${ }^{15}$ Selain itu, Ia disebut "Kudus" karena karya-Nya adalah mengerjakan pengudusan di dalam diri orang percaya. ${ }^{16}$

“.. . adalah Allah yang sejati dan kekal"

Frase "Roh Kudus adalah Allah yang sejati dan kekal" memiliki beberapa pengertian. Pertama, kekal berarti keberadaannya tidak memiliki titik permulaan. Dia tidak diciptakan dan Dia setara dengan Bapa dan Anak dalam natur dan kapasitas-Nya sebagai Allah. Sebelum dunia diciptakan, Ia sudah ada bersama-sama dengan Bapa dan Anak. Ia terlibat aktif dalam penciptaan dunia beserta segala isinya (Kej. 1:1-2). Kedua, kekal juga berarti tidak ada perubahan. Secara hakikat,

${ }^{13}$ Clarence Stam, Living in the Joy of Faith: The Christian Faith as outlined in the Heidelberg Catechism (Canada: Inheritance, 1991), 128.

${ }^{14}$ Herman Hoeksema, The Triple Knowledge, vol. 2, An Exposition of the Heidelberg Catechism (Grand Rapids: Eerdmans, 1947), 152.

${ }^{15} \mathrm{G}$. Van Reenen, The Heidelberg Catechism: Explained for the Humble and Sincere in 52 Sermons (Paterson: Lont \& Overkamp, 1955), 262-263.

${ }^{16}$ Zacharias Ursinus, The Commentary of Dr. Zacharias Ursinus on the Heidelberg Catechism (Philipsburg: P \& R, 1852), 271.
Ia tidak berubah, baik dahulu sekarang dan sampai selama-lamanya. Keberadaan, kedaulatan, dan kuasa-Nya tetap. Ketiga, kekal juga berarti tanpa akhir. Ia bukan ciptaan yang fana tetapi Ia adalah Allah yang akan selama-lamanya hidup dan tidak akan lekang dimakan waktu. ${ }^{17}$

\section{“ . . . bahwa Dia Dikaruniakan Juga Kepa- daku ..."}

Kalimat ini menyatakan bahwa Roh Kudus dikaruniakan kepada orang percaya secara personal. Ia dikaruniakan kepada gereja sebagai tubuh Kristus secara umum dan kepada tiap anggota tubuh Kristus secara personal. ${ }^{18}$ Kita menjadi milik-Nya dan Dia menjadi milik kita. Suatu kepemilikan yang saling bersinergi satu sama lain dan banyak ayat Alkitab yang menyatakan akan hal ini (2Kor. 1:21-22; Ef. 1:13-14; Rm. 8:2, 4, 9, 14-15, 23, 26-27; Gal. 4:4-7). ${ }^{19}$ Karena barangsiapa yang menjadi milik Kristus, berarti Roh Kudus hadir, tinggal, dan berkarya dalam diri orang itu sebagai tanda dan bukti kehadiran Kristus bagi gereja-Nya. ${ }^{20}$

“... supaya Dia Membuat Aku, oleh Iman yang Sejati, Beroleh Bagian dalam Kristus dan Segala Anugerah-Nya ...”

Semua hal di atas hanya dapat terjadi bila "melalui iman yang sejati dan benar" yang dihasilkan oleh karya pengudusan yang Roh Kudus di dalam kehidupan orang percaya. Di sinilah perlu bagi kita untuk membedakan karya pengudusan yang bersifat definitif dan progresif yang dikerjakan oleh Roh Kudus. Pengudusan yang bersifat definitif terjadi pada saat kita bertobat, mengakui segala dosa kita, lalu mengaku, percaya, dan menerima Yesus sebagai Tuhan dan Juru Selamat

\footnotetext{
${ }^{17}$ Tim Departemen Dogma dan Penelitian Sinode Gereja Kristus Tuhan dan Staf Pengajar STT Aletheia, Renungan Harian, 132-133.

${ }^{18}$ Klooster, A Mighty Comfort, 60. 187.

${ }^{19}$ Dawa, Penghiburan dan Sukacitaku Selamanya, 186-

${ }^{20}$ Cornelius Plantinga Jr., A Place to Stand (Grand Rapids: CRC, 1979), 29.
} 
pribadi dalam hidup kita. Tidak bisa dipungkiri kejatuhan Adam yang pertama membuat kita semua terlahir dalam kondisi yang rusak, cemar, dan korup. Segala usaha kita pribadi hanyalah seperti kain usang yang kotor di hadapan Allah. Oleh karena itu, di dalam pengudusan yang definitif ini sepenuhnya hanyalah dan adalah karya mutlak Roh Kudusmonergisme, tanpa campur tangan atau andil manusia apa pun, yang melahirbarukan kita. Tuhan berkata, "Aku, Akulah Dia yang menghapus dosa pemberontakanmu oleh karena Aku sendiri, dan Aku tidak mengingat-ingat dosamu” (Yes. 43:25). Jadi, “. . . kamu bukan lagi orang asing dan pendatang, melainkan kawan sewarga dari orang-orang kudus dan anggota-anggota keluarga Allah" (Ef. 2:19). Pada tahap inilah kita sebagai orang percaya mulai "memperoleh bagian di dalam Kristus," kuasa kasih pengorbanan-Nya di atas kayu salib mulai diaplikasikan oleh Roh Kudus kepada orang percaya sebagai dasar justifikasi bahwa dosa-dosa kita telah ditebus, kita sudah diperdamaikan dengan Allah, dan kita pun telah dipindahkan dari kegelapan kepada terang-Nya yang ajaib.

Setelah kita mengalami pengudusan yang bersifat definitif di atas, maka pengudusan progresif baru berjalan di dalam proses perjalanan kehidupan orang percaya kita alami. Roh Kudus mulai mengaplikasikan secara progresif "segala anugerah" dari karya pendamaian yang Kristus kerjakan di atas kayu salib. Sebagaimana Eliezer, pelayan Abraham (Kej. 24), yang diutus untuk menjemput dan menghantar Ribka, wanita pinangan bagi Ishak, demikianlah pula Roh Kudus menghantar kita kepada persekutuan yang semakin erat dengan Mempelai Agung kita, Kristus. ${ }^{21}$ Sama seperti progresivitas karya Roh Kudus dalam hidup Kristus, yang makin lama makin memunculkan karakter dan peranan mesianik-Nya, mulai dari proses kelahiran (Mat. 1:18; Luk. 1:31, 35); baptisan, pelayanan (Mat. 12:28; Luk. 4:14; Yoh. 1:33-34; Kis. 10:38); kematian, kebangkitan, dan sampai kepada kenaikan-Nya (Rm. 1:4, 6:4; 1Kor. 15:45; Ibr.

\footnotetext{
${ }^{21}$ Reenen, The Heidelberg Catechism, 267; Klooster, A Mighty Comfort, 261.
}

9:14; 1Ptr. 3:18), begitu pulalah karya Roh Kudus dalam diri orang percaya yang membentuk diri kita semakin lama semakin serupa Kristus (Rm. 8:29), dari derajat kemuliaan satu kepada kemuliaan lainnya (2Kor. 3:1718).

Namun, di dalam tahap pengudusan ini, meski orang percaya sudah dibebaskan dari perhambaan oleh dosa dan dikuduskan melalui darah Kristus, dalam kehidupan sehariharinya orang percaya masih bisa jatuh bangun dalam mengiring Kristus dan berbuat dosa. Oleh karena itu, pengudusan di tahap ini melibatkan tanggung jawab setiap orang percaya untuk berpartisipasi aktif dan bekerja sama dengan Roh Kudus (sinergisme). Ada harga yang harus dibayar dan tergantung sekarang apakah di dalam proses pengudusan itu orang percaya tersebut mau menyerahkan dirinya untuk dipimpin Roh atau tetap hidup dalam kedagingan dan kepuasaan nafsu duniawi semata.

$$
\text { “... Menghibur Aku ...” }
$$

Roh Kudus adalah Roh "Penghibur." Kata "Penghibur" di sini berasal dari kata Yunani paraklete (Yoh. 15:26) dan memiliki makna berbeda seperti yang dipahami oleh orangorang dunia pada umumnya. Secara populer, kata penghibur sering kali dilekatkan kepada seseorang yang bisa membuat orang lain tertawa, seperti pelawak atau komedian. Pengertian umum lainnya, penghibur juga bisa bermakna orang yang memberikan kesenangan dan kepuasan hawa nafsu, seperti wanita penghibur atau pria penghibur. Namun, semua penghiburan yang dimaknai dan ada dalam dunia ini adalah penghiburan yang semu dan menyesatkan serta membuat manusia makin jatuh ke dalam masalah, dosa, dan malapetaka. Namun, Roh Kudus berbeda. Ia memberikan penghiburan sejati dan kekal yang dunia tidak bisa berikan. Penghiburan yang diberikan oleh-Nya tidak terlepas dari pribadi Kristus. Roh Kudus tidak memberikan penghiburan di luar apa yang telah diajarkan oleh Kristus dan penghiburan yang dikerjakan oleh Roh Kudus membawa orang 
percaya untuk memuliakan Kristus dan bukan memuliakan yang lain.

Lebih lanjut, penghiburan yang dikerjakan oleh Roh Kudus mencakup tiga aspek. Aspek yang pertama, Roh Kudus memberikan penghiburan bagi mereka yang terluka, putus asa, dan berdukacita. ${ }^{22}$ Ia menyembuhkan orang yang patah hati dan membalut luka-luka mereka (Mzm. 147:3). Ia memberikan pengharapan bagi mereka yang berputus asa dalam menghadapi pengujian Allah dan pengharapan itu tidaklah mengecewakan (Rm. 5:5). Ia juga menghibur mereka yang berdukacita karena kebenaran (Mat. 5:4). Aspek kedua, Roh Kudus memberikan penghiburan kepada mereka yang lemah dan tak berdaya. ${ }^{23}$ Roh Kudus membangkitkan semangat, harapan, serta keberanian dalam diri orang percaya agar mereka dapat hidup bagi Kristus dan dapat menjadi saksi-Nya di tengah dunia. Aspek terakhir, Roh Kudus memberikan pertolongan kepada orang percaya dalam menghadapi berbagai macam persoalan hidup, kelemahan, serta keterbatasan mereka. ${ }^{24}$ Ia tidak membiarkan kita dicobai melampaui kekuatan kita. Ia akan memberikan jalan keluar yang terbaik bagi kita menurut waktu dan cara-Nya sehingga kita akan tangguh dalam menanggung dan menghadapi pencobaan itu (1Kor. 10:13).

\section{“... dan Menyertai Aku Selama-lamanya”}

Terakhir, Roh Kudus akan menyertai kita selama-lamanya. Menyertai memiliki arti selalu dekat dengan seseorang. Namun, arti menyertai di sini bukan sekadar bahwa Roh Kudus dekat, bersama, atau menemani kita, tetapi juga berarti bahwa Ia memberikan hikmat dan pengertian kepada kita untuk memilih jalan manakah yang benar dan yang tidak (1Kor. 2:13). Ia tetap membimbing kita untuk tetap melangkah di jalan yang benar

\footnotetext{
${ }^{22}$ R. C. Sproul, Kebenaran-kebenaran Dasar Iman Kristen, terj.Rahmiati Tanudjaja (Malang: Literatur SAAT, 2000), 160.

${ }^{23}$ Ibid., 160.

${ }^{24}$ Tim Departemen Dogma dan Penelitian Sinode Gereja Kristus Tuhan dan Staf Pengajar STT Aletheia, Renungan Harian, 135-136.
}

dan menjaga orang percaya dari segala jerat yang dipasang oleh Iblis yang digambarkan dalam Alkitab seperti singa yang mengaumaum dan selalu mencari kesempatan untuk menyerang dan memangsa domba-domba yang lemah tidak berdaya (1Ptr. 5:8). Selain itu, Ia juga menegur dan mengarahkan kita kembali apabila jalan kita mulai melenceng. Penyertaan-Nya tidak bergantung pada kondisi orang percaya. Ketika orang percaya jatuh ke dalam dosa, Roh Kudus tidak sertamerta meninggalkan dan absen dari kehidupan orang percaya tersebut. Roh Kudus tetap hadir dan akan menggelisahkan orang percaya tersebut untuk tidak tetap berkubang dalam dosa-dosanya atau terus-menerus melakukan perbuatan dosa tersebut. Semua bentuk penyertaan Roh Kudus ini bersifat instruksional dan relasional, menjaga kita agar tetap berada, berakar, bertumbuh, dan berbuah di dalam relasi kovenan kekal kita dengan Allah Tritunggal hingga masa konsumasi nanti (Yud. 1:24).

\section{Konteks Ketiga (Present Context)}

Bila dikaitkan dengan konteks kekristenan dan Indonesia masa kini, setidaknya ada dua poin relevansi yang bisa ditarik dari penelitian ini. Pertama, tidak terlalu berbeda dengan kondisi kekristenan yang melatarbelakangi penyusunan $\mathrm{KH}$ pada waktu itu, kekristenan di Indonesia saat ini juga mengalami perpecahan dan pertikaian yang tak terkira. Hal ini tidak hanya terjadi di antara mereka yang punya warna dan rumpun teologi yang berbeda, tetapi juga di antara mereka yang memiliki warna dan rumpun teologi yang sama atau mirip. Faktornya tidak hanya masalah teologis, tetapi faktor-faktor dan kepentingankepentingan lain juga turut serta di dalamnya, seperti: keinginan untuk berkuasa dan mendominasi, tidak ingin rugi (balik modal), permasalahan pribadi, dan lain sebagainya. Hal ini ironis, miris, tetapi sangat realistis. Gereja mengalami perpecahan di sana sini. Bahkan, STT-STT yang ada di Indonesia juga mengalami perpecahan.

Malahan tak jarang, isu teologis diperalat dan ditunggangi supaya terkesan mulia padahal 
tujuannya adalah untuk menyerang dan menjatuhkan sesamanya. Dalam hal ini, di manakah jejak-jejak karya Roh Kudus secara realistis yang telah mempersatukan kita di dalam Kristus? Apakah kedamaian dan persatuan di antara anggota tubuh Kristus yang menjadi doa Tuhan Yesus dalam Yohanes 17:21 hanyalah utopia belaka, menjadi sesuatu yang ada dalam bayangan tetapi tidak pernah ada dalam pegangan? Marilah kita mulai mengusahakannya dari sekarang! Alangkah indahnya bila satu gereja tidak melihat gereja lain sebagai saingan dan sinode lain sebagai lawan.

Namun, dengan rendah hati hendaklah kita belajar untuk saling melengkapi satu sama lain sebagai sesama anggota tubuh Kristus yang telah diadopsi melalui karya Roh Kudus. Gereja yang lemah dalam hal pemuridan dapat belajar dari gereja yang telah memiliki sistem pemuridan yang baik. Para pemimpin gereja yang berbeda satu sama lain dapat hadir dan duduk bersama dengan penuh kehangatan dan keterbukaan di dalam acaraacara seperti Badan Musyawarah Gereja, dan lain-lain. STT-STT yang ada sebaiknya saling melengkapi satu sama lain, saling membantu mempromosikan kebaikan atau acara-acara dari STT lain (tidak hanya STT sendiri). Sebaiknya STT-STT aktif hadir bersama dengan penuh kesantunan dan penerimaan di dalam acara-acara yang diadakan, misal: PERSETIA, PASTI, dan lain-lain. Selain itu, seyogyanya mereka saling meningkatkan kualitas satu sama lain, bertukar pengajar, dan mengizinkan dosen yang ahli di bidang tertentu untuk mengajar di STT lain (tidak dimonopoli sendiri), dan masih banyak lagi.

Kedua, mengemukanya ide "Revolusi Mental" yang didengung-dengungkan oleh Jokowi selama masa kampanye Pilpres 2014 dan yang akan dijalankannya selama pemerintahan lima tahun depan seakan "membangunkan" semua orang Indonesia akan parahnya kemerosotan moral yang sedang dan terus-menerus menggerus bangsa Indonesia. Hal ini sebenarnya merupakan tamparan tersendiri bagi kekristenan di Indonesia. Bukankah "Revolusi Mental" seharusnya lebih diperdengarkan dan dinyatakan oleh kalangan roha- niwan dan para pendidik moral? Di manakah peran para pemimpin gereja dan pendidik Kristen selama ini? Bukankah orang Kristen yang sudah mengalami kelahiran baru oleh Roh Kudus dan menjalani proses pengudusan yang progresif seharusnya menjadi garam dan terang yang nyata dan dapat dirasakan serta berdampak bagi sekelilingnya?

Saat ini jumlah doktor di Indonesia sekitar 40 ribu orang dan sebagian besar merupakan doktor di bidang sosial dan agama. Berarti bukankah kekristenan di Indonesia memiliki cukup banyak doktor di bidang pendidikan agama. Ke manakah mereka semua? Menjadi rohaniwan di gereja? Menjadi pengajar di sekolah, universitas Kristen, atau STT? Apa lagi yang masih kurang? Yang dapat menjadi pertanyaan adalah sebenarnya sudah sejauh manakah para pemimpin gereja dan pendidik Kristen peduli terhadap pertumbuhan Kristen yang nyata bagi umat dan peserta didik mereka? Misal, apakah gereja pernah membuat suatu evaluasi atau survei dari sekian banyak jemaat mereka yang selama ini beribadah dan melayani? Perubahan apa yang mereka alami dalam hidup mereka, kesulitan apa yang menghambat mereka untuk berubah? Atau jangan-jangan gereja selama ini hanya berjalan bak "robot," yang penting semuanya berjalan seperti biasanya, jemaat tidak berkurang, datang beribadah setiap minggu, dan malah kalau bisa bertambah? Program, kegiatan, dan suara dari mimbar pun akhirnya bak uap belaka, tidak mengena dan bermakna bagi jemaat. Lalu, untuk para pendidik Kristen, sejauh manakah pernah disusun dan dijalankan satu kurikulum pendidikan yang rapi, holistik, dan cukup terukur bagi peserta didik mereka, yang entah nantinya akan terjun di marketplace ataupun di gereja, dan lembaga pelayanan lainnya?

Kiranya orang lain mengenal Tuhan melalui karya Roh Kudus yang nyata melalui hidup kita.

Deum agnoscis ex operibus ejus! (terj.: orang mengenal Tuhan dari karya-Nya) 


\section{Daftar Kepustakaan}

Bierma, Lyle D. An Introduction to Heidelberg Catechism: Sources, History, and Theology. Grand Rapids. Baker, 2005.

Burger, Hans. "Gospel Presentation and the Structure of the Heidelberg Catechism." Diakses 11 Desember 2014. https://www.academia.edu/3772581/Gospel_Presentation_and_the_ Structure_of_the_Heidelberg_Catechism (diakses pada 11 Desember 2014).

Halsema, Thea B. Van. Three Men Came to Heidelberg and Glorious Heretic: The Story of Guido de Brès. Grand Rapids: Baker, 1991.

Heideman, Eugene P. "God the Holy Spirit." Dalam Guilt, Grace, and Gratitude: A Commentary on the Heidelberg Catechism, diedit oleh Donald J. Bruggink. New York: The Half Moon Press, 1963.

Hoeksema, Herman. The Triple Knowledge. Vol. 2, An Exposition of the Heidelberg Catechism. Grand Rapids: Eerdmans, 1947.

Klooster, Fred H. A Mighty Comfort. Grand Rapids: CRC, 1990.

Latzel, Thorsten. Theologische Grundzüge des Heidelberger Katechismus: eine fundamentaltheologische Untersuchung seines Ansatzes zur Glaubenskommunikation. Vol. 83, Marburger theologische Studien. Marburg: N. G. Elwert, 2004.

Dawa, Mariani Febriana Lere. Penghiburan dan Sukacitaku Selamanya: Suatu Uraian Katekismus Heidelberg. Malang: Bayumedia, 2014.

Plantinga, Jr., Cornelius. A Place to Stand. Grand Rapids: CRC, 1979.

Reenen, G. Van. The Heidelberg Catechism: Explained for the Humble and Sincere in 52 Sermons. Paterson: Lont \& Overkamp, 1955.

Sproul, R. C. Kebenaran-kebenaran Dasar Iman Kristen. Diterjemahkan oleh Rahmiati Tanudjaja. Malang: Literatur SAAT, 2000.

Stam, Clarence. Living in the Joy of Faith: The Christian Faith as outlined in the Heidelberg Catechism. Canada: Inheritance, 1991.

Tim Departemen Dogma dan Penelitian Sinode Gereja Kristus Tuhan dan Staf Pengajar STT Aletheia. Renungan Harian menurut Katekismus Heidelberg I. Surabaya: Rachmat Printing, 2011.

Ursinus, Zacharias. The Commentary of Dr. Zacharias Ursinus on the Heidelberg Catechism. Philipsburg: P \& R, 1852.

Ursinus, Zakharias dan Caspar Olevianus. Katekismus Heidelberg: Pengajaran Agama Kristen. Edisi revisi. Diterjemahkan oleh Tim BPK Gunung Mulia. Jakarta: BPK Gunung Mulia, 2013.

Verboom, Wim. "The Completion of the Heidelberg Catechism." Dalam The Church's Book of Comfort. Diedit oleh Willem Van 'T Spijker. Diterjemahkan oleh Gerrit Bilkes. Grand Rapids: Reformed Heritage Books, 2009. 